\title{
Uterine rupture at 28 weeks of gestation after laparoscopic myomectomy - a case report
}

\author{
Katarzyna M. Tomczyk, Maciej Wilczak, Paweł Rzymski \\ Department of Mother and Child Health, Poznan University of Medical Sciences, Poznan, Poland
}

\begin{abstract}
There are many reasons for sterility, and uterine malformations are of the greatest concern. Among uterine disorders, myomas play a significant role and are present in $27 \%$ of infertile women. The occurrence of myomas is frequent $-20-40 \%$ in women of reproductive age. Thus, for those infertile patients surgical treatment may be needed to preserve an opportunity to conceive.

This case report refers to an uterine rupture at 28 weeks of gestation after laparoscopic myomectomy (3 months before conceiving). The myomectomy was conducted correctly and two layers of sutures on the myometrium were performed.

The purpose of the myomectomy in a young woman should be well considered. In cases of infertility, removal of the lesions is usually necessary to give the patient a chance of pregnancy. At the same time, the risk of uterine rupture is increased. There are some suggestions referring to myomectomy to reduce the risk of uterine rupture in a subsequent pregnancy. It seems that the method of sewing the uterine closure is crucial. For example, multilayer uterine stitches, preservation of the endometrial cavity, and avoidance of using electrosurgery to prevent devascularization (to avoid haematoma formation) should be taken into consideration to prevent weakness of the wall of the uterus. Uterine scars differ histologically and biochemically.
\end{abstract}

Key words: uterine rupture, myoma, myomectomy.

\section{Introduction}

There are many reasons for sterility; for example, failure of ovulation, tubal and uterine malformations, cervical mucus, sperm defects, and endometriosis are of the greatest concern [1]. Among uterine disorders, myomas play a significant role and are present in $27 \%$ of infertile women [2, 3]. The occurrence of myomas is frequent $20-40 \%$ in women of reproductive age [4]. There is an increasing amount of evidence that all kind of myomas submucosal, intramural and subserosal - may be a cause of sterility (in decreasing order of importance) [5]. Thus, for those infertile patients surgical treatment, myomectomy, is important and needed to preserve an opportunity to conceive. However, the effectiveness and safety of the subsequent pregnancy is still uncertain. This paper describes the medical case of a pregnant patient who had undergone laparoscopic myomectomy and experienced uterine rupture in week 28 of gestation.

\section{Case presentation}

A 27-year-old woman had undergone laparoscopic myomectomy 3 months before conception. A subsero- sal myoma $10 \mathrm{~cm}$ in diameter was located on the posterior wall of the uterus. The myometrium was sewn with 2 layers of stitches. Bipolar diathermy was used to maintain haemostasis. The surgery was uncomplicated. The patient conceived 3 months later without medical contraindications. The course of the pregnancy was uncomplicated. The ultrasound scans of the fetus, placenta and uterus were normal.

In week 28 of gestation the patient came to the Emergency Department because of sudden abdominal pain and nausea. The obstetrical examination revealed a formed uterine cervix, the cervical orifice closed and increased uterine tension.

Ultrasound examination revealed that the position of the fetus was transverse. There were no signs of placenta abruption. In the cardiotocography (CTG) sinusoid oscillation and decelerations were observed, and after that the patient was immediately transported to the delivery ward (Fig. 1). After 15 minutes of CTG monitoring an immediate caesarean section was performed due to sinusoid oscillation and progressive abdominal pain. The fetus within the amniotic sac, as well as the placenta, was partially expelled into the abdominal cavity. A uterine rupture of $6 \mathrm{~cm}$ on the posterior wall was found. 


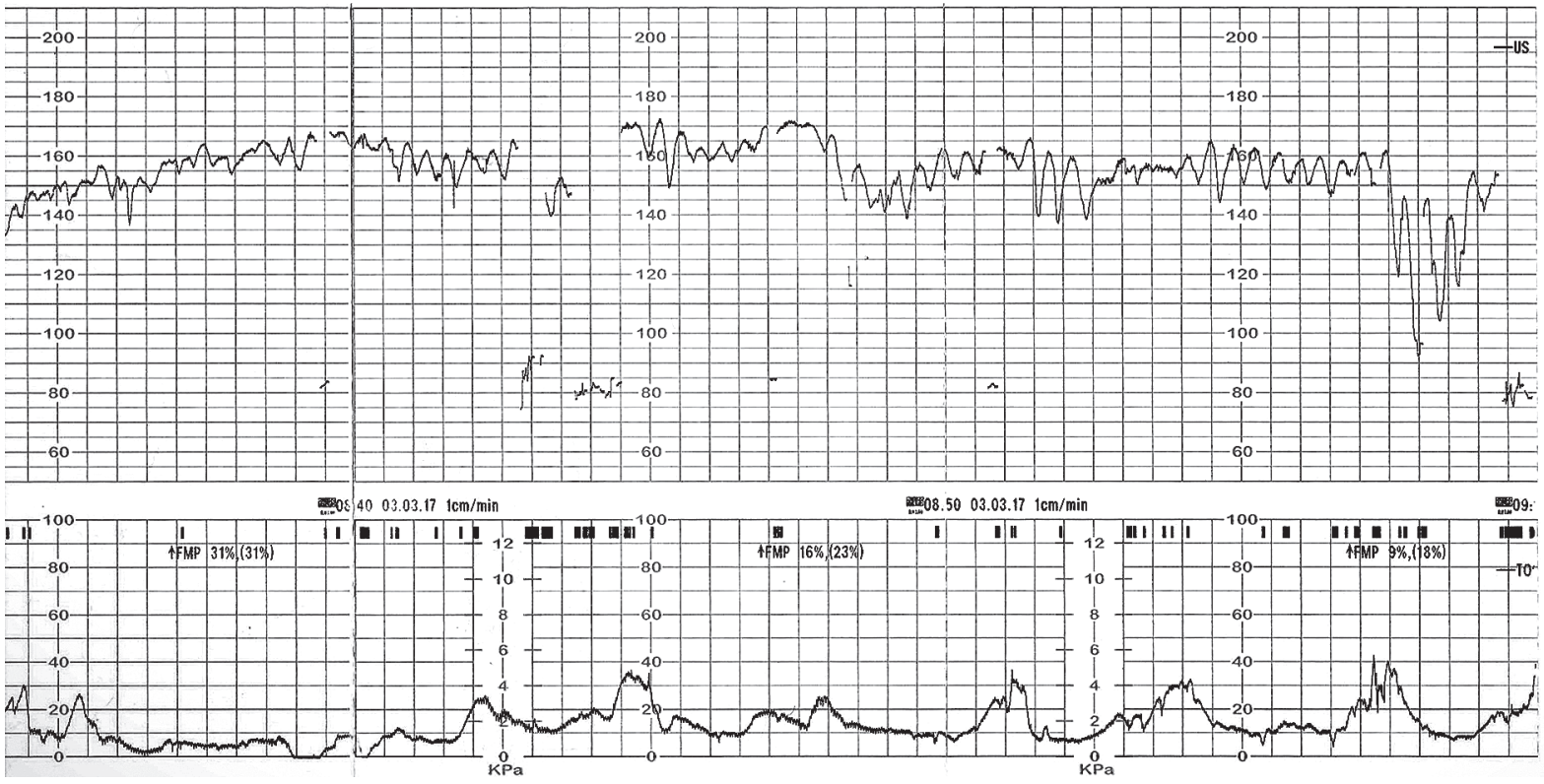

Fig. 1. Cardiotocography during admission

A boy was born alive, weight $1455 \mathrm{~g}$, Apgar scale: 0 , $0,0,2,4$. Because of intraperitoneal bleeding the patient needed transfusion of $4 \times 400 \mathrm{ml}$ of erythrocyte concentrate and $2 \times 100 \mathrm{ml}$ of plasma. Further pharmacologic agents including antibiotics - cefuroxime axetil $3 \times 1500 \mathrm{mg}$ i.v., amikacin $2 \times 500$ mg i.m., metronidazole $3 \times 500 \mathrm{mg}$ i.v. - as well as enoxaparin $40 \mathrm{mg} / \mathrm{ml}$ and painkillers were administered. The patient was discharged in a good condition on the $7^{\text {th }}$ day after surgery.

\section{Discussion}

The incidence of uterine rupture is low, at around $0.012 \%$ in cases without previous uterine scars [6]. The total risk of rupture after abdominal myomectomy is $0-4 \%$ and after laparoscopy $0-1 \%[7,8]$. It seems that uterine ruptures after caesarean section occur more commonly [9]. The evidence suggests that both techniques are effective in terms of future pregnancy $[5,10]$. Laparoscopy is associated with quicker recovery, lower risk of adhesions and a better cosmetic result [10, 11]. On the other hand, it is a more difficult technique. Advantages of both techniques: laparoscopy and laparotomy compounded mini-laparotomy seem to be as effective and safe and should also be considered [12]. It seems that it is not the surgical technique, but the method of sewing the uterine closure that is crucial [11-13]. Bipolar diathermy coagulation seems to weaken the wall of the uterus, and hence may be a future cause of uterine rupture during pregnancy $[11,13,14]$. Most authors indicate that the 2-layer closure with stitches is essential to maintain the resistance of the womb's wall $[11,13,14]$. The size and number of removed myomas, and the opening of the endometrial cavity, may also be potential factors that may increase the risk of uterine rupture. Nevertheless, due to limited evidence in this field these factors remain a topic for debate.

In most cases, uterine rupture after myomectomy occurs during the third trimester or in labour [14]. However, Hamideh et al. described a case of uterine rupture in week 20 of gestation in a patient after abdominal myomectomy 6 years before conception [6]. However, Braun et al. noted 120 pregnancies after abdominal myomectomy (AM) with no uterine rupture and deliveries on time [7]. Similarly, Golan et al. reported 59 uncomplicated pregnancies after laparoscopic myomectomy [15]. Kumakiri et al. showed that vaginal deliveries may be safe after laparoscopic myomectomy (LM). From 111 pregnant patients after LM, 59 underwent natural deliveries successfully and 52 had caesarean sections (CS). No uterine rupture was observed [16]. Another interesting case report by Ivka illustrated that uterine rupture may occur even after one successful natural delivery in a patient after LM [17]. In terms of LM, Koo et al. studied 523 women after LM and found a uterine rupture incidence of $0.6 \%$ [18]. Bernardi et al. observed $10 \%$ of uterus rupture in 55 analyzed patients after LM, and the average time to conception was 73.5 months [19]. In contrast, Okada et al. described a case of uterine rupture even in week 10 of gestation after laparoscopic myomectomy, and therefore the occasional occurrence of uterine rupture after surgery of the uterus even in the first trimester should be considered [20].

Uterus healing consists of various processes: blood clotting, inflammation, new tissue formation and tissue remodelling. The tissue remodelling process has not been fully investigated. However, it has been reported 
Table 1. Cases of uterine rupture during pregnancy after previous myomectomy

\begin{tabular}{lccc}
\hline $\begin{array}{l}\text { Time of uterine rupture } \\
\text { (week of gestation) }\end{array}$ & Method of myomectomy & $\begin{array}{l}\text { Time of surgery before } \\
\text { conception (year) }\end{array}$ & Author \\
\hline 20 & Laparotomy & 6 & Hamideh et al. [6] \\
\hline 16 & Laparotomy & 6 & Al-Ramahi et al. [14] \\
\hline 10 & Laparoscopy & 1 & Okada et al. [20] \\
\hline 23 & Laparoscopy & 8 & Kiseli et al. \\
\hline 32 & Laparoscopy & 1.5 & Sutton et al. [39] \\
\hline 30 & Laparoscopy & & Tsankova et al. \\
\hline
\end{tabular}

that the injured uterus compared to the unscarred wall of the womb is characterized by:

- similar endometrium layer,

- no perimetrium layer as well as defective scar area,

- decreased uterine wall thickness,

- increased VEGF and PDGF immunoreactivity [21].

The scar/wound healing is the result of synthesis and degradation of extracellular matrix. Growth factors as well as proteolytic enzymes such as elastase and collagenase are involved in the process [22]. Histologically, the main problem of the uterine scar is collagen deposition and its impact on native, baseline cells [23]. Collagen seems to alter the proliferation, differentiation and migration of the basalis layer of the endometrium; thus the wall of the uterus is weaker [23]. Pollio's study confirmed that the scars of women with uterine dehiscence contain higher collagen content [24]. Moreover, in the scar a reduction of expression of transforming factor- $\beta$ (TGF- $\beta$ ) and an increase in basic fibroblast growth factor were found [24]. However, it seems that fibromodulin may improve scar strength [25]. Moreover, recent studies showed that anti-oxidative enzymes may play a significant role in the uterus healing process [21].

The study of Wu et al. revealed that smooth muscle volume density was significantly lower in uterine scars after CS (until 7 years after CS) compared to those without previous CS. Also in the group of patients with a scar (up to 3 years after surgery) the number of apoptotic nuclei was higher and significantly lower in the group that had CS 7-9 years before. The conclusion was that the uterine scar becomes mature at even 9 years after surgery [26].

There are no studies about the resistance of the uterine scar with respect to the intensity of uterus contractions. It seems that the injured uterus should be considered as an individual case.

Ultrasound evaluation of the caesarean uterine scar is essential. Many publications confirm that attributes of the quality of the scar include: scar thickness of $3.5 \mathrm{~mm}$ or more, the homogeneity of the scar, triangular shape of the scar, richer perfusion, and scar volume verified by $3 \mathrm{D}$ technique up to $10 \mathrm{~cm}[27,28]$.
Another important issue is the time of conception after myomectomy. There is no strict recommendation, yet it seems that 6 months of recovery is the minimum time for the uterus to cicatrize. However, a longer time is also proposed, as it is much safer for a developing fetus. Al-Ramahi et al. noted a case of uterine rupture even in week 16 of gestation after abdominal myomectomy 6 years before conception [14]. It seems there are some other factors that may need to be taken into account. The following table (Table 1) presents cases of uterine ruptures after myomectomy due to the time of the surgery.

Rupture of the gravid uterus is a life-threatening condition for the fetus and the mother. It is necessary to perform CS as fast as possible to have a chance of saving the baby and the woman. Ten to 37 minutes is the recommended time after uterine rupture for delivering a baby and avoiding fetal morbidity [29]. The first symptoms of uterine rupture are not characteristic, so it may be difficult to establish the diagnosis. The first common sign is fetal bradycardia - up to $87 \%$ of observed cases [30]. Sudden abdominal pain, vomiting and nausea are also common [30]. Vaginal bleeding and maternal hypovolemic shock are also described [31-33].

The purpose of the myomectomy in young woman should be well considered [17]. In cases of infertility, surgery and removal of the lesions is usually necessary to give the patient a chance of pregnancy. At the same time, the risk of uterine rupture is increased. Other risk factors of uterine rupture include congenital uterine anomalies, labour induction, uterine trauma and other previous surgical procedures on the uterus, including particularly caesarean section, abdominal and laparoscopic surgery, intrauterine procedures, obstetric manoeuvres and injudicious use of oxytocin [2, 13, 15]. Uterine rupture can occur in an intact uterus but this condition is very rare [34-36].

There are some suggestions referring to myomectomy to reduce the risk of uterine rupture in a subsequent pregnancy. For example, multilayer uterine stitches, preservation of the endometrial cavity, and avoidance of using electrosurgery to prevent devascularization as a prevention of haematoma formation should be used to prevent weakness of the wall of the uterus [37-39]. 


\section{Conclusions}

The purpose of myomectomy in young women should be well considered.

Uterine rupture after myomectomy may occur during every trimester in subsequent pregnancies.

Multilayer uterine stitches as well as preservation of the endometrial cavity should be maintained during myomectomy (laparoscopic and abdominal).

\section{Disclosure}

The authors report no conflict of interests.

\section{References}

1. Casini ML, Rossi F, Agostini R, Unfer V. Effects of the position of fibroids on fertility. Gynecol Endocrinol 2006; 22: 106-109.

2. Practice Committee of the American Society for Reproductive Medicine in collaboration with Society of Reproductive Surgeons. Myomas and reproductive function. Fertil Steril 2008; 90 (5 Suppl): S125-130.

3. Borgfeldt C, Andolf E. Transvaginal ultrasonographic findings in the uterus and the endometrium: low prevalence of leiomyoma in a random sample of women age 25-40 years. Acta Obstet Gynecol Scand 2000; 79: 202-207.

4. Bulletti C, Dez D, Levi Setti P. Myomas, pregnancy outcome, and in vitro fertilization. Ann NY Acad Sci 2004; 1034: 84-92.

5. Somigliana E, Vercellini P, Daguati R, et al. Fibroids and female reproduction: a critical analysis of the evidence. Hum Reprod Update 2007; 13: 465-476.

6. Hamideh P, Soofizadeh N, Beigom Khezri M. Spontaneous uterine rupture after abdominal myomectomy at the gestational age of 20 weeks in pregnancy: A case report. Int J Reprod Biomed (Yazd) 2016; 14: 483-486.

7. Brown AB, Chamberlain R, Te Linde RW. Myomectomy. Am J Obstet Gynecol 1956; 71: 759-763.

8. Garnet JD. Uterine rupture during pregnancy. An analysis of 133 patients. Obstet Gynecol 1964; 23: 898-905.

9. Lieng $\mathrm{M}$, Istre O, Langebrekke A. Uterine rupturę after laparoscopic myomectomy. J Am Assoc Gynecol Laparosc 2004; 11: 92-93.

10. Miller CE. Myomectomy. Comparison of Open and Laparoscopic Techniques. Obstet Gynecol Clin North Am 2000; 27: 407-420.

11. Sizzi O, Rossetti A, Malzoni M, et al. Italian multicenter study on complications of laparoscopic myomectomy. J Minim Invasive Gynecol 2007; 14: 453-462.

12. Księżakowska-Łakoma K, Żyła M, Wilczyński J. Removal of uterine fibroids by mini-laparotomy technique in women who wish to preserve their uterus and fertility. Videosurgery Miniinv 2016; 10: 561-566.

13. Buckley VA, Nesbitt-Hawes EM, Atkinson P, et al. Laparoscopic myomectomy: clinical outcomes and comparative evidence. J Minim Invasive Gynecol 2015; 22: 11-25.

14. Al-Ramahi M, Radi F, Oatawneh A, AlKazaleh F. Spontaneous Uterine Rupture at 16-week Gestation After Abdominal Myomectomy. J Med J 2009; 43: 351-354.

15. Golan A, Sandbank O, Rubin A. Rupture of the pregnant uterus. Obstet Gynecol 1980; 56: 549-554.

16. Kumakiri J, Takeuchi $\mathrm{H}$, Itoh $\mathrm{S}$, et al. Prospective evaluation for the feasibility and safety of vaginal birth after laparoscopic myomectomy. J Minim Invasive Gynecol 2008; 15: 420-424.

17. Djaković I, Sabolović Rudman S, Djaković Ž, Košec V. Uterine rupture following myomectomy in third trimester. Acta Clin Croat 2015; 54: 521524.

18. Koo YJ, Lee JK, Lee YK, et al. Pregnancy outcomes and risk factors for uterine rupture after laparoscopic myomectomy: a single-center experience and literature review. J Minim Invasive Gynecol 2015; 22: 1022-1028.

19. Bernardi TS, Radosa MP, Weisheit A, et al. Laparoscopic myomectomy: a 6-year follow-up single-center cohort analysis of fertility and obstetric outcome measures. Arch Gynecol Obstet 2014; 290: 87-91.
20. Okada Y, Hasegawa J, Mimura T, et al. Uterine rupture at 10 weeks of gestation after laparoscopic myomectomy. J Med Ultrason 2016; 43: 133-136.

21. Sayin O, Micili S, Goker A, et al. The role of resveratrol on full- thickness uterine wound healing in rats. Taiwan J Obstet Gynecol 2017; 56: 657-663.

22. Czarkowska-Paczek B, Przybylski J. Mechanism of tissue repair. Prz Lek 2004; 61: 39-42.

23. Xu L, Ding L, Wang L, et al. Umbilical cord - derived mesenchymal stem cells on scaffolds facilitate collagen degradation via upregulation of MMP-9 in rat uterine scars. Stem Cell Res Ther 2017; 8: 84.

24. Pollio F, Staibano S, Mascolo M, et al. Uterine dehiscence in term pregnant patients with one previous cesarean delivery: Growth factor immunoexpression and collagen content in the scarred lower uterine segment. Am J Obstet Gynecol 2006; 194: 527-534.

25. Zheng Z, James AW, Li C, et al. Fibromodulin reduces scar formation in adult cutaneous wounds by eliciting a fetal-like phenotype. Signal Transduct Target Ther 2017; 2: pii: 17050.

26. Wu C, Chen X, Mei Z, et al. A preliminary study of uterine scar tissue following cesarean section. J Perinat Med 2018; 46: 379-386.

27. Basic E, Basic-Cetkovic V, Kozaric H, et al. Ultrasound evaluation of uterine scar after cesarean section. Acta Inform Med 2012; 20: 149-153.

28. Qureshi B, Inafuku K, Oshima K, et al. Ultrasonographic evaluation of lower uterine segment to predict the integrity and quality of cesarean scar during pregnancy: a prospective study. Tohoku J Exp Med 1997; 183: 55-65

29. Nahum G, Pham K. Uterine Rupture in Pregnancy. Medscape 2012; http://reference.medscape.com/article/275854

30. Bujold E, Mehta SH, Bujold C, Gauthier RJ. Interdelivery interval and uterine rupture. Am J Obstet Gynecol 2002; 187: 1199-1202.

31. Ravasia DJ, Brain PH, Pollard JK. Incidence of uterine rupture among women with mullerian duct anomalies who attempt vaginal birth after cesarean delivery. Am J Obstet Gynecol 1999; 181: 877-881.

32. Eden RD, Parker RT, Gall SA. Rupture of the pregnant uterus: a 53-year review. Obstet Gynecol 1986; 68: 671-674.

33. Uzun I, Yildirim A, Kalelioglu I, Has R. Spontaneous rupture of unscarred uterus at 27 weeks of gestation. Arch Gynecol Obstet 2010; 281: 999-1001.

34. Gardeil F, Daly S, Turner MJ. Uterine rupture in pregnancy reviewed. Eur J Obstet Gynecol Reprod Biol 1994; 56: 107-110.

35. Hockstein S. Spontaneous uterine rupture in the early third trimester after laparoscopically assisted myomectomy A case report. J Reprod Med 2000; 45: 139-141.

36. Seracchioli R, Manuzzi L, Vianelli F, et al. Obstetric and delivery outcome of pregnancies achieved after laparoscopic myomectomy. Fertil Steril 2006; 86: 159-165.

37. Buckley VA, Nesbitt-Hawes EM, Atkinson P, et al. Laparoscopic myomectomy: clinical outcomes and comparative evidence. J Minim Invasive Gynecol 2015; 22: 11-25.

38. Flyckt R, Falcone T. Uterine rupture after laparoscopic myomectomy. J Minim Invasive Gynecol 2015; 22: 921-922.

39. Sutton C, Standen P, Acton J, Griffin C. Spontaneous Uterine Rupture in a Preterm Pregnancy following Myomectomy. Case Rep Obstet Gynecol 2016; 2016: 6195621. 